\title{
INITIAL DEBATE AS AN INNOVATIVE METHOD TO INTRODUCE A NEW SUBJECT
}

\author{
Raquel Sanchis, Raul Poler \\ Research Centre on Production Management and Engineering (CIGIP), Universitat \\ Politècnica de València (SPAIN)
}

\begin{abstract}
The first class of a course is normally devoted to introducing students to the different aspects of a subject such as the themes, contents, evaluation methods, professors, contact information, among others. However, the first class is normally considered by students an unimportant one as there is little interaction between educators and them. The first class is generally a master lecture and students' participation is unusual. In order to overcome this tiresome situation, this paper proposes an innovative method where an initial debate is performed. The main conclusions of such debate are registered with twofold objectives. Firstly, the professor obtains valuable information about the initial students' knowledge level related to the aspects of the subject in order to adapt the subject's features to fulfil efficiently the learning objectives. Secondly, the responses obtained through the debate are used during the running of the course to show students the differences between their first impression and the real and exact meaning of the different aspects included in the subject. This method is applied in a subject of an Engineering Master Degree as an original method to help professors in their teaching activities and motivate students in their learning activities.
\end{abstract}

Keywords: Initial Debate, Innovative Method, Subject Introduction, Engineering Master Degree, Students' Knowledge Level.

\section{INTRODUCTION}

The first day of class is a very important time for faculty to establish a tone for what will happen the rest of the semester. It is appropriate that a lecturer reflects on just what climate and first impression she/he would like to establish [1].

Some educators only devote the first day merely to preliminaries, handing out a syllabus, giving an assignment, and dismissing the class. For this reason, the first class is normally considered by students an unimportant one as there is little interaction between educators and them [2].

In the first day class, it is very important to explain the course expectations, the subject themes and contents, the learning materials (textbook, slides, ...) and how students have to use them, the educators involved in the subject (if there are more than one), the educators' contact information (email addresses, office...), how students will be evaluated, among others. But not only these formal aspects are important but on one hand educators also highlight the relevance, in this first day class, to assess students in order to quantify their related subject knowledge and categorised this knowledge into basic, medium or high level. This piece of information will be very valuable to adapt subject contents and the depth with which these contents will be explained during the running of the course, based on the results of this initial evaluation. On the other hand, other educators also point out that it is worth performing any kind of ice-breaker activity to make students feel comfortable and also motivated with the new subject.

For this reason, in this paper, we propose an initial debate as an innovative method to introduce a new subject. Performing and encouraging a debate in the first day class provides appreciated information about the initial students' knowledge level, enables students familiarise with new terms and concepts and serves as an ice-breaker activity. Therefore, the objective of this paper is to describe the general methodology developed to perform the initial debate and offer a real implementation example in a subject taught in an Engineering Master Degree.

The paper is structured as follows. Section 2 describes the methodology used in the first class to perform a debate as an innovative method to introduce a new subject. Section 3 describes the implementation of such a methodology in a real case. And finally, section 4 is devoted to the conclusions of this article. 


\section{FIRST-CLASS METHODOLOGY: INITIAL DEBATE}

The initial debate as an innovative method to introduce the contents of a new subject is based on the following methodology that consists of 7 steps. Figure 1 shows an overview of the methodology developed for the initial class.

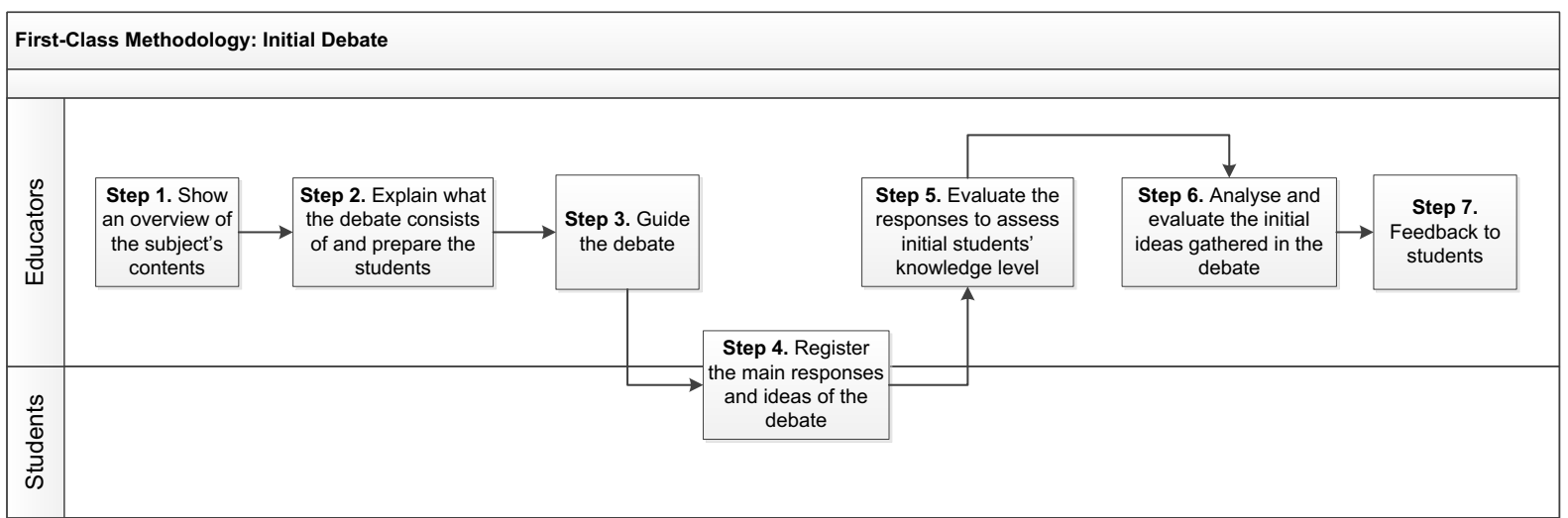

Figure 1. Methodology to perform an initial debate for the first day class.

\section{+ Step 1. Show an overview of the subject's contents.}

It is important to introduce to students the educational contents that will be studied in the subject. For this reason, the educator should go over the topics of the course and let students know how the course is organized and the links with other subjects of the degree and/or master. However, in this step, it is recommended to show the contents superficially and not go into detail. The goal is to make students have a preliminary overview about the main elements of the subject without digging into details, since too much information can limit the freewheeling nature of the debate. Following this strategy, the objective is to provide a first overview of the subject's contents to try to capture students' attention but without providing deep information since the debate will later deepen.

\section{+ Step 2. Explain what the debate consists of and prepare the students}

It is highly recommendable that the educator explains that the following activity to be performed is a debate.

Students should understand that the objective of the debate is to generate responses to guided questions about the contents of the subject to, in this first class, deepen all together and in a collaboratively way, into the educational contents of the subject. In this way, the active learning is promoted as, the students with their responses; shape the meaning and significance of the concepts of the subject. One of the most important things in this step is to make clear that the students' responses are not officially assessed as if students perceive that they are being evaluated, they will feel inhibited and this will impact negatively in their participation in the debate.

Although it is worth mentioning that, without students' perception, educators, through the debate performance, will obtain appreciated information about the initial students' knowledge level. Educators will be able to detect lack of knowledge in basic concepts necessary to achieve successfully the learning objectives what will help them to decide about the reinforcement of some basic aspects of the subject. Educators should try to keep a relaxed and cheerful environment to encourage students' participation.

\section{+ Step 3. Guide the debate}

Educators should initiate the debate through a set of questions that should be answered by students. The questions should be related to basic but also more advanced content of the subject. The debate may be performed individually, however, it is advisable to make groups of 3-4 students to share the responsibility of the responses and then, make them feel more comfortable in answering. 
Educators should have the ability to, once students have responded to the first questions, start a discussion to define other related concepts and use them to create and define new ones. It is also important to show to students the links and connections with other subjects or contents. Educators should encourage students to contribute and answer the questions, including the quietest ones, and discourage anyone from criticizing responses.

Educators should guarantee that a good number of different responses for each question has been generated. With regard to the duration of the debate, a typical debate should last not more than 30 minutes. Longer sessions tend to make student lose interest. However, in the case that longer debate is necessary, breaks could be taken.

\section{+ Step 4. Register the main responses and ideas of the debate}

It is necessary to register the main responses of each of the issues raised during the debate. This could be done anonymously, that is, to register the responses without the information about who provided such responses or register the information with whom answered each aspect. This depends on the educators' choice. Some educators prefer to record the information without names so students do not feel embarrass when answering. However, others prefer to register who, to perform in a more personalized way, the assessment of step 6.

The registration of the debate ideas and responses could be done in many ways. However, the current information and communication technologies enable to register data online and in a very easy way. An example of these technologies is the use of Goggle Docs [3] where both educators and students can write simultaneously their contributions. This is a very relaxed and simple way to register the information obtained through the debate. However, the selection of the way to register the information depends on the educators' preferences.

\section{+ Step 5. Evaluate the responses to gather information about the initial students' knowledge level}

Whether the record of information is anonymous or not, educators can assess the responses and obtain a first impression about students' knowledge level. When the responses to a specific basic question are generally not correct, the educator should not correct students, but the information should be recorded to advise educators that such a basic aspect should be reinforced during the running of the course. Therefore, this activity of initial debate serves as diagnostic tool to quantify the starting knowledge level of students. Some authors such as [4] point out the importance of knowing the starting knowledge level to not leave in the queue any student for not having the basic notions. However, to obtain this piece of information, most of educators use formal tools such as tests. With the use of an informal initial debate as a ludic activity, the information collection is less stressful for students and the reliability of the information can be even greater than with traditional methods.

\section{+ Step 6. Analyse and evaluate the initial ideas gathered in the debate}

To provide feedback to students (Step 7), it is important to structure and organize the information gathered during the initial debate. Depending on how the educator has guided the debate, the information could have been recorded in an unorganised way. Therefore, educators are responsible to shape and consolidate the information to be shown in each session. If the course is organised in e.g. four lessons, the information should follow the same arrangement and should be divided into these four lessons.

\section{+ Step 7. Feedback to students}

This is an on-going activity that will be performed during at the running of the course. After, this first day class, the course develops based on the planned programme. However, in each session, when different educational contents are explained and understood by the students, the educators should show the initial impressions, responses and ideas gathered during the initial debate to see if students were right or they had a very different vision about the already explained concepts.

This feedback can be also used before the explanation or during the explanation of the concept/s. This will depend on the educators' preferences. This activity breaks a bit with the monotony of the master classes and makes students pay more attention. Moreover, this review of the initial debate ideas and responses impact students what makes them remember more easily the definition of the concept that the educator has just explained than on other occasions. 


\section{APLICATION IN AN ENGINEERING MASTER DEGREE SUBJECT}

The methodology described in section 2 was applied in the Subject "Demand and Supply Management" taught in the "Master Degree in Organization and Logistics Engineering" at Universitat Politècnica de València (Spain). In the first class of such a subject, after providing general information such as classes calendar, professors involved in the educational process, evaluation methods, ...among other, the educator used the previous methodology:

\section{+ Step 1. Show an overview of the subject's contents.}

The main contents of the subject are shown in Figure 1. The subject is divided into two main parts. The first one related to the demand perspective and the second one addressed to supply aspects. The demand part is, in turn, divided into two lessons, one devoted to demand forecasting and the second one addressed to demand management. The supply part has also two lessons, one devoted to order fulfilment strategies and the last one dedicated to replenishment systems. This piece of information was the one that is provided to students. The items of each lesson were briefly described to offer a simple overview of the subject.

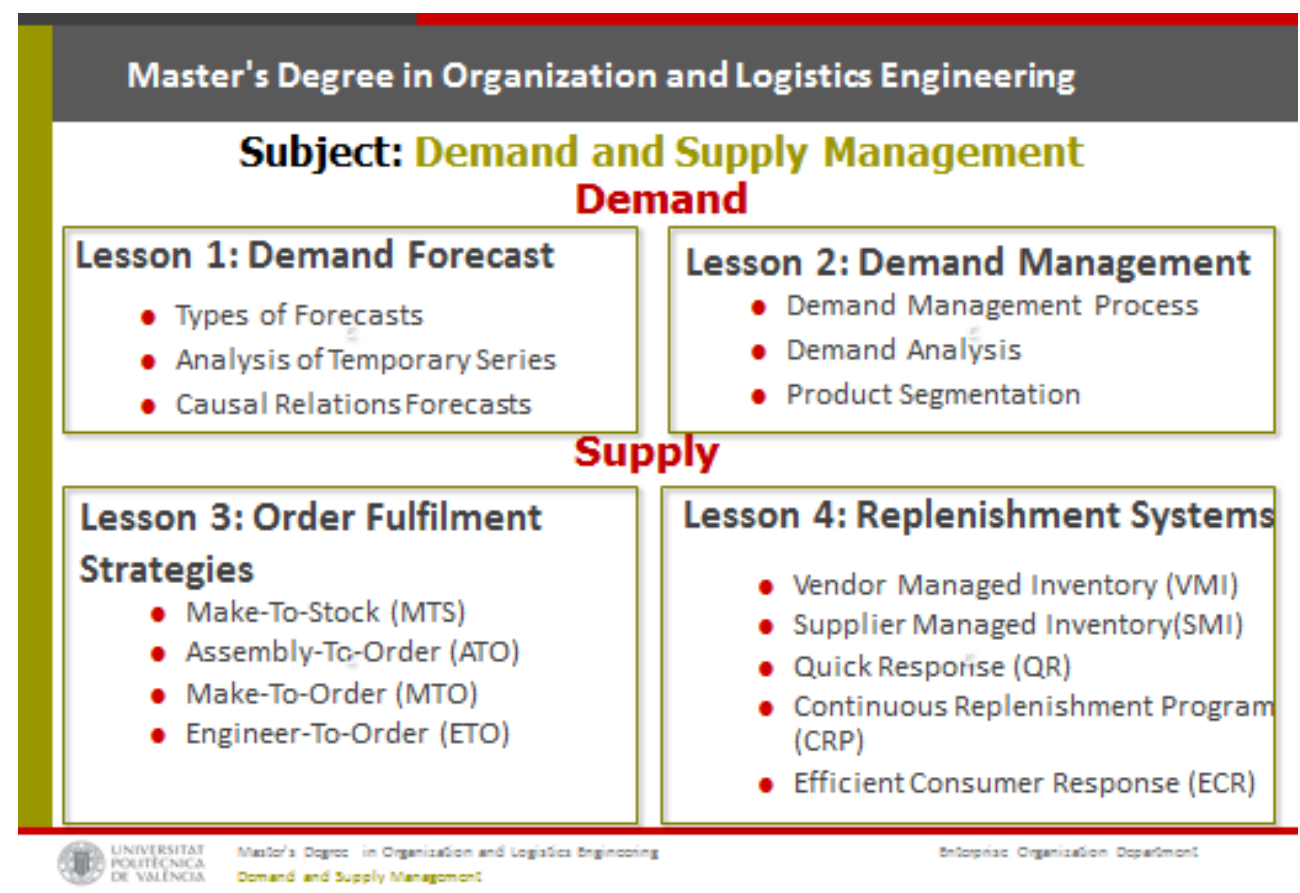

Figure 2. Main contents of the subject "Demand and Supply Management".

\section{+ Step 2. Explain what the debate consists of and prepare the students.}

In this step, the educator explained that a debate was going to be performed. In this case, groups of 4 students were done to make them feel more comfortable, since in this way, they do not to have to answer individually or express their ideas alone. 


\section{Master's Degree in Organization and Logistics Engineering}

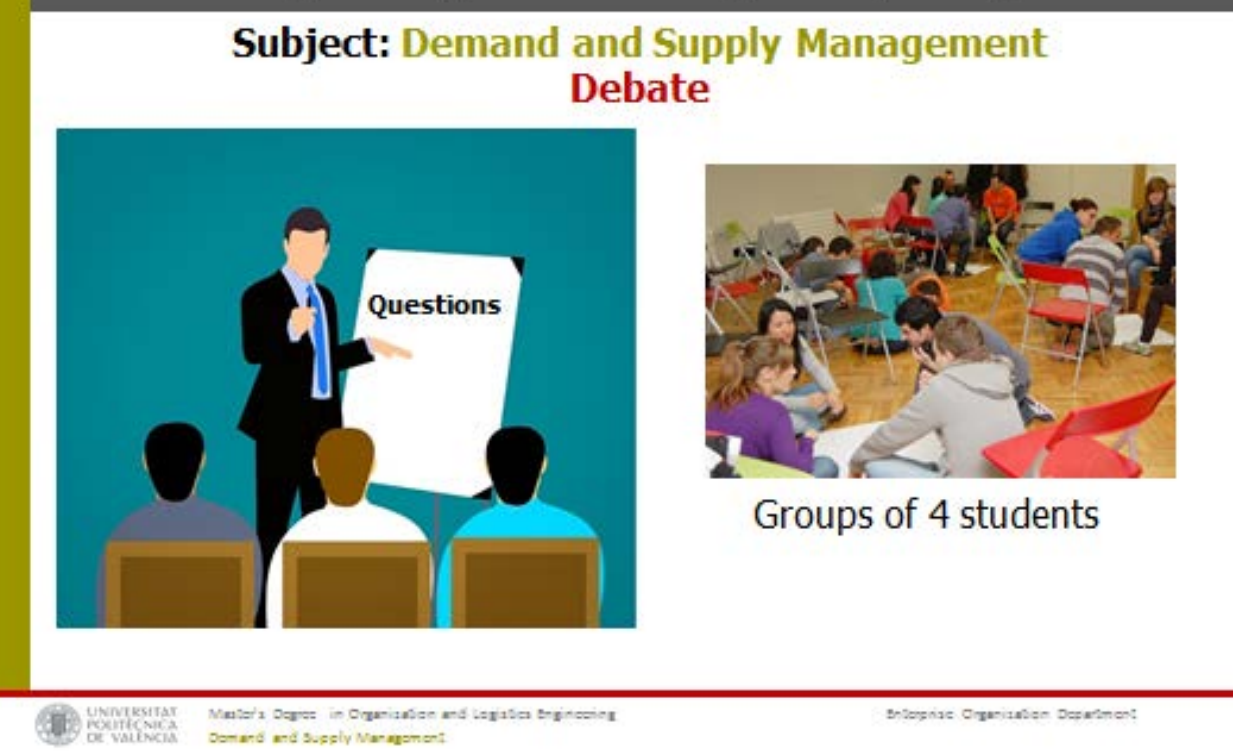

Figure 3. Slide to explain what the debate consists of and prepare the students.

\section{+ Step 3. Guide the debate.}

During the activity, the educator initiates the debate with a set of questions, in this case the debate was initiated with questions related to lesson 1 . The questions posed by the educator with regard lesson 1 were the following ones:

$\checkmark$ Do you know what the demand forecast is?

$\checkmark$ Do you know any software tool for demand forecasting?

$\checkmark$ Have you ever forecasted a demand?

$\checkmark$ Do you thing that all companies make demand forecasting?

$\checkmark$ What methods do you think companies use to forecast demand?

$\checkmark \quad$ What variables do you think can influence the demand of a specific product?

Based on these questions, the responses of the students and the contents of the subject, the educator should have the ability to (i) encourage the discussion and (ii) formulate the appropriate next questions to align the debate to the educational matters of the subject.

+ Step 4. Register the main responses and ideas of the debate.

In this step, all the students' groups had access to a Google Document on Drive (the same for everybody) where they wrote their responses anonymously. One of the advantages of using Google docs is the feature of view history by which educators can see the history record of information made by students to compare the initial ideas with the definitive ones written by them, or if they have kept the initial ones.

\section{+ Step 5. Evaluate the responses to gather information about the initial students' knowledge level.}

Steps 5 and 6 have common aspects, as in both cases the goal is to analyse the information recorded. Nevertheless, in this step, the objective is to get an assessment about initial students' knowledge level related to the contents of each of the 4 lessons. While, in step 6 , the analysis is focused on analysing and organizing the information following the structure of the four lessons to give feedback to students in an orderly way during the course development. 


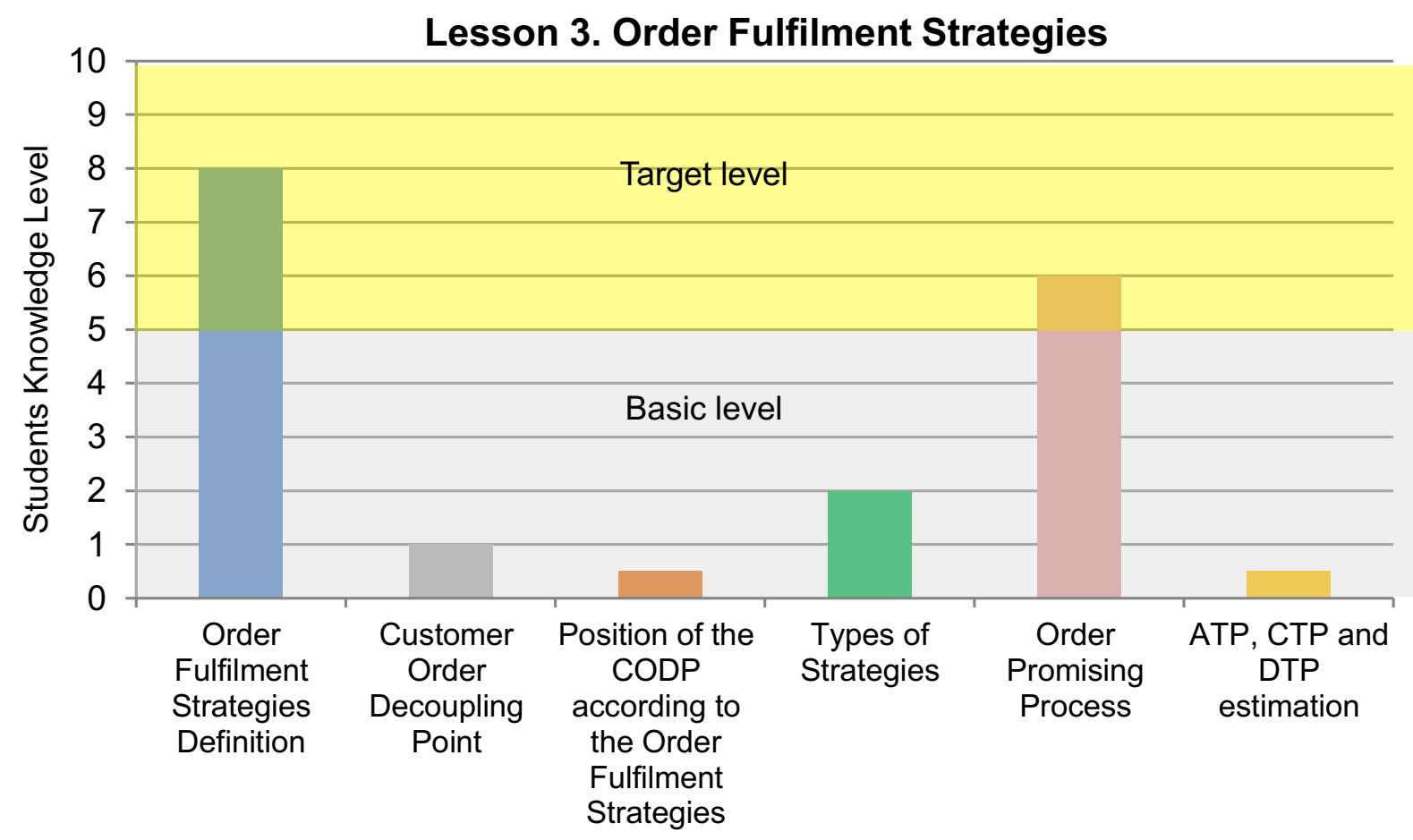

Figure 4. Assessment of the Students' Knowledge Level of Lesson 3

For example, the results obtained after the initial debate with regard to lesson 3 are described as follows. Students had a basic notion about what the order fulfilment strategies are, however they did not know neither the different types of strategies nor the Customer Order Decoupling Point (CODP) significance. As they had no knowledge about the CODP, and the previous two concepts are related, students were not able to distinguish the different positions of this point depending on the order fulfilment strategy selected. Another important aspect was to find out if students already had notions about the order promising process and if they were able to recognise how to perform the process and calculate the Available-To-Promise (ATP), Capable-To-Promise (CTP) and Deliver-To-Promise (DTP). As it is shown in Figure 4, students were able to define, more or less, what order promising process consist of but they had no idea about the calculation of ATP, CTP and DTP of a specific problem. Therefore, through the results obtained, the educator has a first overview to decide about which concepts should be explained in more detail and which ones are already understood.

The information represented in Figure 4 is confidential and students are not aware of this analysis, since it is not a formal assessment but it is a diagnostic information to help educators in the preparation of the running of the course. This data is only used as informative source to support educators in the development of the educational process.

\section{+ Step 6. Analyse and evaluate the initial ideas gathered in the debate.}

The main goal of this step is to make a compilation in an orderly way of all the responses gathered during the session of the initial debate. Moreover, it is important not only to represent the students' responses and ideas discussed during the debate but to add the reliable information about the concepts asked. Figure 5 is a Goodle Doc document that was developed after the first day debate session. In this document, the educator put in order the different responses classified by topic and lesson. In this case, the topic is the definition of the CODP, concept explained in lesson 3. Besides this, the precise definition of this term with some references is added to provide feedback to students. 


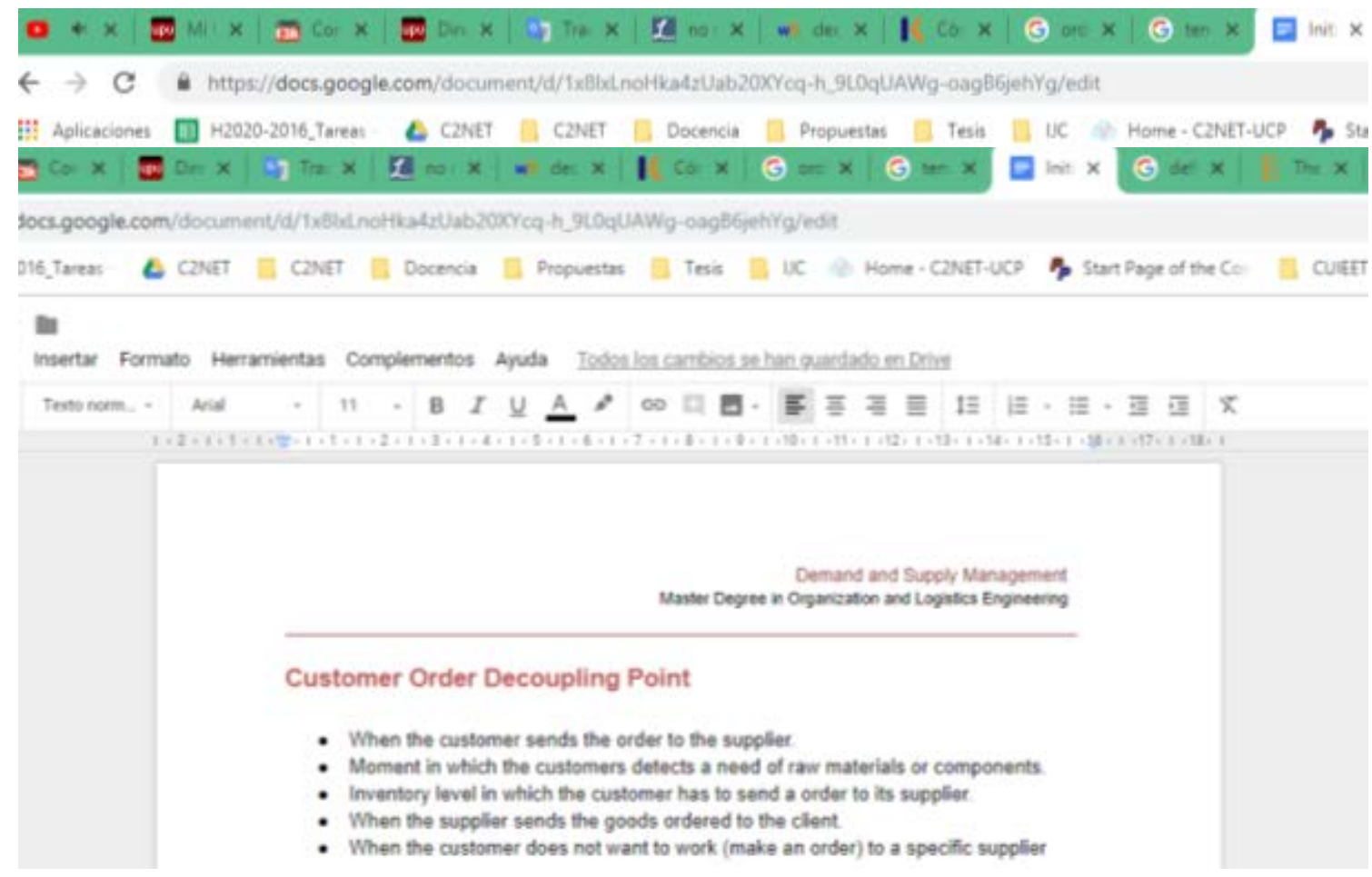

Figure 5. Feedback to students.

\section{+ Step 7. Feedback to students.}

Based on the document developed in Step 6 and shown in Figure 5, the educator, during the running of the course, show the different documents to make students visualize the different between what they though at the beginning of the course and what really is. This feedback can be used before the explanation of the concept, during the explanation of such term taking advantage of the collection of information during the debate, or after, once that the concept has been explained and students have understood the term. The third alternative is the one that it is usually used when the responses and the ideas gathered during the debate are very ludicrous. After the explanation, the educator shows students' initial thinking and the feedback impacts them and in most of the cases, makes them laugh, because the difference between the real meaning and whet they though at the beginning of the course. It is important to highlight that an impressive aspect, such as the feedback, enables to capture students' attention and besides, makes students remember the concepts more easily.

\section{CONCLUSIONS}

The paper describes the general methodology used to perform an initial debate in the first day class. This innovative method provides valuable information from twofold perspectives.

Firstly, through the responses of students, educators are able to quantify their starting knowledge level to, in first instance, focus the learning process on the basic ones that presents lack of understanding.

Secondly, the responses of the debate are recorded to be shown during the running of the course to provide feedback to students, this feedback consists of presenting their initial responses to a specific questions and the correct responses. This feedback makes students to be aware about the differences between their initial thinking and the real significance.

Moreover, this type of activity is beneficial in the first class, as it is an ice-breaker one and in the first day class, it is important to create a comfortable atmosphere where students feel welcome.

The paper also describes the real implementation of the methodology in the Subject "Demand and Supply Management" taught in the "Master Degree in Organization and Logistics Engineering" at Universitat Politècnica de València (Spain).

The methodology can be applied to any educational programme of any degree or master. The methodology defined is a general one and depending on the subject in which the initial debate is going 
to be performed and the information requirements of educators, the methodology should be adapted and/or customized.

\section{REFERENCES}

[1] D. L. Wright, "The most important day: Starting well," Teaching and Learning Center, University of Nebraska, 1999. Retrieved from URL. http://honolulu. hawaii. edu/intranet/committees/FacDevCom/guidebk/teachtip/dayone. htm.

[2] Santandfor Teachin Commons, "Preparing for the First Class," Standford University, 2019. Retrieved from URL. https://teachingcommons.stanford.edu/resources/course-preparationresources/course-preparation-handbook/preparing-first-class

[3] Google Docs, "Google Documents", Google, 2019. Retrieved from URL. https://www.google.es/int//en/docs/about/

[4] R. Barajas, P. Saavedra, J. Albéniz, \& I. Carrillo, "The importance of knowing the starting level of knowledge," Multidisciplinary Journal for Education, Social and Technological Sciences, vol. 1, no. 1, pp. 69-82, 2014. 